\title{
Mechanism of Peripheral Substituent Effects on Adsorption- Aggregation Behaviors of Cationic Porphyrin Dyes on Tungsten(VI) Oxide Nanocolloid Particles
}

\author{
Naoya KANETADA, Chiyoe MATSUMURA, Suzuko YAMAZAKI, and Kenta ADACHI*. \\ Department of Environmental Science \& Engineering, Graduate School of Science \& Engineering, \\ Yamaguchi University, Yamaguchi, 753-8512, Japan. \\ Tel \& Fax: +81-83-933-5731.
}

* To whom correspondence should be addressed. E-mail: k-adachi@yamaguchi-u.ac.jp 


\begin{abstract}
The adsorption and aggregation behaviors of the cationic porphyrin derivatives such as $5,10,15,20$ tetrakis(4-pyridyl)porphyrin [TPyP], 5,10,15,20-tetrakis( $N$-methyl-4-pyridyl)porphyrin $\quad$ [TMPyP], 5,10,15,20-tetrakis( $N$-ethyl-4-pyridyl)porphyrin $\quad$ [TEPyP], and $\quad 5,10,15,20$-tetrakis $(N$ - $n$-propyl-4pyridyl)porphyrin [TPPyP] (hereafter called "TPyP derivatives") in the tungsten(VI) oxide $\left(\mathrm{WO}_{3}\right)$ colloid aqueous solution at weak acidic $\mathrm{pH}$ were studied by UV-Vis spectroscopy. The TPyP derivatives were strongly adsorbed as monolayer onto the $\mathrm{WO}_{3}$ surface via the electrostatic interaction between their peripheral cationic substituents and negatively surface-charged $\mathrm{WO}_{3}$ colloid particles, and most of ones adsorbed eventually formed $J$-type dimers aligned in the head-to-tail fashion. These different dimerization states were effectively analyzed by the change of ratios among the intensities of exciton split Soret bands $(H-$ and $J$-bands). Judging from the exciton coupling theory and adsorption measurements, we concluded that the $J$-dimer geometry of the TPyP derivatives adsorbed on the $\mathrm{WO}_{3}$ colloid particle surface is strongly dependent on the presence and difference of peripheral substituents. The results described here indicate a new and promising way of designing surface supramolecular structures combination of two principles, the selfassociation of organic dyes and the steric repulsive interaction between the peripheral substituents and the inorganic semiconductor surfaces.
\end{abstract}

Keyword; porphyrin, tungsten oxide, adsorption, aggregation, self-organization 


\section{INTRODUCTION}

Molecular organization has recently gained more and more interest. The exploration of the organized molecules can not only help us understand the self-organization behavior of organic molecules in a biological system, but can also help us assemble novel functional materials in a designed way and fabricate molecular devices or supramolecular devices. ${ }^{1-4}$ Recently, supramolecular nanoaggregates in terms of porphyrin building blocks have been attracting great interest due to their potential application possibilities in various fields of general concern. ${ }^{5-8}$ Especially, they play many critical roles in the biological systems, such as oxygen transport, enzymatic catalysis, and light-harvesting. Some of the functions of porphyrins are strongly related to their supramolecular organizations. ${ }^{9}$ For example, in natural photosynthetic systems, chlorophylls, which are structurally similar to porphyrin, are often self-organized into nanoscale suprastructures by which they perform many of the light-harvesting and energy/electron transferring functions. ${ }^{10}$ Therefore, it is an issue of paramount importance to control the assembly of porphyrins. Several porphyrin-based supramolecular nanostructures have been successfully assembled in a solution by using various surfactants as a structure-directing template. ${ }^{11-14}$

Nowadays, there has been considerable research interest focused on the study of photophysicochemical properties, aggregations, and absorption behaviors of organic dye molecules on the surface of inorganic semiconductor materials. These studies can provide invaluable information that serves as guidance for fabrication of high performance dye-based electronic devices. ${ }^{15-17}$ One of the key requirements in the operation of this kind of devices is the sensitization of a wide band gap semiconductor via electron injection from a photoexcited dye molecule. It should be noted that the efficiency of the electron transfer step at the dye-semiconductor interface is highly dependent, among numerous other factors, on the way that the organic dye molecule is attached; ${ }^{18-24}$ thus, tailoring the optoelectronic properties of the organic-inorganic hybrid nanocomposites would be achieved by assembling well-defined layers of organic dye molecules on the two-dimensional surface of inorganic semiconductor nanoparticles. However, to our knowledge, there 
have been several literature reports on the organic dye-inorganic semiconductor nanoparticle interactions, but only limited quantitative information is available on the adsorption and aggregation mechanism. ${ }^{25-27} \mathrm{~A}$ universal approach of controllable assembly of dye molecules on the inorganic semiconductor surface, which will endow organic/inorganic hybrid materials with innovative features that the corresponding monomeric dye could not perform, still remains very challenging but quite an urgent task at present.

We report herein new efforts to understand the surface adsorption-aggregation properties of porphyrin dyes on the tungsten(VI) oxide $\left(\mathrm{WO}_{3}\right)$ nanocolloid particles and their excited-state interactions. $\mathrm{WO}_{3}$ is an intensively studied representative of a group of metal-oxide semiconductors with a wide band gap $(<3.0 \mathrm{eV})$, and it is well-known for its unique characteristics such as photocatalytic activity, photo- and electrochromic coatings and microelectronic applications. ${ }^{28-30}$ In addition, there has been a great deal of recent interest in the $\mathrm{WO}_{3}$ nanocrystals and thin films for the development of smart windows for energyefficient architecture of buildings and automobiles, flat-panel displays, optical memory and writing-readingerasing devices, and electronic information displays, because of its photochromic and electrochromic properties. ${ }^{31,32}$ More recently, it has been demonstrated that photochromic $\mathrm{WO}_{3}$ colloid particles exhibit colorimetric sensing properties for amino acid compounds in aqueous solutions, which will have numerous applications in continuous in vivo monitoring. ${ }^{33}$ Four water-soluble porphyrin dyes having different substituent groups at the peripheral pyridyl-4N positions $(5,10,15,20$-tetrakis(4-pyridyl)porphyrin [TPyP], 5,10,15,20-tetrakis( $N$-methyl-4-pyridyl)porphyrin [TMPyP], 5,10,15,20-tetrakis( $N$-ethyl-4-pyridyl)porphyrin [TEPyP], and 5,10,15,20-tetrakis( $N$ - $n$-propyl-4-pyridyl)porphyrin [TPPyP]), meanwhile, have been studied. In the present work, we describe the key role of peripheral substituents of these porphyrin derivatives, which can influence both the adsorption as well as the aggregation behaviors on the $\mathrm{WO}_{3}$ colloid surface. Our investigation discloses a potential regulatory role of peripheral substituents in terms of surface supramolecular nanoassembly. 


\section{EXPERIMENTAL}

\subsection{Materials}

5,10,15,20-Tetrakis(4-pyridyl)porphyrin (TPyP) was purchased from TCI (Tokyo, JAPAN) and and recrystallized from a chloroform/methanol mixture before use. The water used for all sample preparation was first distilled and then passed through a Milli-Q system (Millipore, USA), resulting in the specific resistivity of $18.2 \mathrm{M} \Omega \mathrm{cm}$. All other chemicals were of reagent grade from Nacalai Tesque Inc. (Kyoto, Japan) or Wako Pure Chemical (Osaka, Japan), and were used as received without further purification.

\subsection{Size-Controlled Preparation of $\mathrm{WO}_{3}$ Particles.}

The preparation procedure of $\mathrm{WO}_{3}$ colloidal particles is similar to that described in the literature. ${ }^{26}$, ${ }^{34} \mathrm{Na}_{2} \mathrm{WO}_{4} \cdot 2 \mathrm{H}_{2} \mathrm{O}(100 \mathrm{~g}, 0.3 \mathrm{~mol})$ was dissolved in $100 \mathrm{~mL}$ of water. Conc. $\mathrm{HCl}(7 \mathrm{~mL}, 0.7 \mathrm{M})$ was added dropwise into the solution with efficient stirring. Eventually, a colorless transparent aqueous $\mathrm{WO}_{3}$ colloid solution ( $\mathrm{pH} 3.3,0.023 \mathrm{M} \mathrm{WO}_{3}$ ) was obtained, which was then closed in a dialysis membrane pipe (3500 Da molecular cut-off; Spectrum Laboratories, CA, USA) and dialyzed in a 1000-mL beaker containing Milli-Q water for a period of $8 \mathrm{hrs}$. The Milli-Q water was periodically replaced until chloride ions could not be detected by ion chromatography. The concentration of chloride ion in the $\mathrm{WO}_{3}$ colloid solution was determined by using portable-type IC analyzer (PIA-1000, Shimadzu, Japan) equipped with an anionexchange Shim-pack IC-A3 column (Shimadzu, Japan) at $30^{\circ} \mathrm{C}$. The eluent used in this study was 4hydroxybenzoic acid $\left(8.0 \times 10^{-3} \mathrm{M}\right) /$ bis(2-hydroxyethyl)iminotris-(hydroxymethyl)methane (Bis-Tris; $3.2 \times 10^{-}$ ${ }^{3} \mathrm{M}$ ), and the flow rate was $300 \mu \mathrm{L} / \mathrm{min}$.

\subsection{Synthesis of 4-Pyridyl- $N$-Alkyl-Substituted TPyP Derivatives.}

Three structurally variant 4-pyridyl- $N$-alkyl-substituted TPyP derivatives [5,10,15,20-tetrakis $(N$ methyl-4-pyridyl)porphyrin (TMPyP), 5,10,15,20-tetrakis( $N$-ethyl-4-pyridyl)porphyrin (TEPyP), and 
5,10,15,20-tetrakis( $N$ - $n$-propyl-4-pyridyl)porphyrin (ТPРyP)] were synthesized with TPyP and the corresponding alkyl iodides (methyl iodide, ethyl iodide, and $n$-propyl iodide, respectively) according to the reported method. ${ }^{35,36}$ Briefly, TPyP $(0.32 \mathrm{mmol})$ and excess alkyl iodide $(0.1 \mathrm{~mol})$ were successively added to dimethylformamide (DMF, $100 \mathrm{~mL}$ ) at room temperature. After being refluxed for ca. $2 \mathrm{hrs,} \mathrm{the} \mathrm{crude}$ product was recrystallized from a hot methanol/diethyl ether mixture to give the required derivative as a purple powder.

TMPyP: Yield: 70.4\%; ${ }^{1} \mathrm{H}$ NMR (400MHz, DMSO-d 6 , $\left.\delta\right):-3.13$ (s, 2H, NH), 4.73 (s, 12H, N$\mathrm{CH}_{3}$ ), 8.98 (d, 8H, meso-phenyl-metha), 9.18 (s, 8H, $\beta$-pyrrol), 9.48 (d, 8H, meso-phenyl-ortho); MALDITOF-MS m/z: 1187 [TMPyP+4I-]+H ${ }^{+}$; Anal. calcd. for $\mathrm{C}_{44} \mathrm{H}_{38} \mathrm{~N}_{8} \mathrm{I}_{4}: \mathrm{C}, 44.54 ; \mathrm{H}, 3.23 ; \mathrm{N}, 9.44$. Found : C, 44.58; H, 3.34; N, 9.37.

TEPyP: Yield: $64.2 \% ;{ }^{1} \mathrm{H}$ NMR $\left(400 \mathrm{MHz}, \mathrm{D}_{2} \mathrm{O}, \delta\right): 1.81\left(\mathrm{t}, 12 \mathrm{H},-\mathrm{CH}_{3}\right), 4.90\left(\mathrm{q}, 8 \mathrm{H}, \mathrm{N}-\mathrm{CH}_{2}-\right)$, 8.85(d, 8H, meso-phenyl-metha), 9.01(s, 8H, $\beta$-pyrrol), 9.24(d, 8H, meso-phenyl-ortho); MALDI-TOF-MS m/z: 1243 [TEPyP+4I- $]+\mathrm{H}^{+}$; Anal. calcd. for $\mathrm{C}_{48} \mathrm{H}_{46} \mathrm{~N}_{8} \mathrm{I}_{4}: \mathrm{C}, 46.40 ; \mathrm{H}, 3.73 ; \mathrm{N}, 9.02$. Found : C, 46.52; $\mathrm{H}$, $3.88 ; \mathrm{N}, 8.98$.

TPPyP: Yield: 59.5\%; ${ }^{1} \mathrm{H}$ NMR (400MHz, $\left.\mathrm{D}_{2} \mathrm{O}, \delta\right): 1.31\left(\mathrm{t}, 12 \mathrm{H},-\mathrm{CH}_{3}\right), 2.42\left(\mathrm{se}, 8 \mathrm{H},-\mathrm{CH}_{2}-\right)$, 4.98(t, 8H, N-CH $\left.2^{-}\right), 9.00(\mathrm{~d}, 8 \mathrm{H}$, meso-phenyl-metha), 9.21(s, 8H, $\beta$-pyrrol), 9.48(d, 8H, meso-phenylortho); MALDI-TOF-MS m/z: 1299 [TPPyP+4I-]+H $\mathrm{H}^{+}$; Anal. calcd. for $\mathrm{C}_{52} \mathrm{H}_{54} \mathrm{~N}_{8} \mathrm{I}_{4}$ : C, 48.09; H, 4.19; N, 8.63. Found : C, 48.12; H, 4.44; N, 8.37.

\subsection{Other Apparatus.}

Elemental analyses were performed using a Perkin-Elmer series II CHNS/O analyzer 2400. Nitrogen adsorption-desorption isotherm was measured at $-195.8^{\circ} \mathrm{C}$ with a TriStar II 3020 analyzer (Micromeritics, USA). Dried $\mathrm{WO}_{3}$ colloid samples (ca. $0.5 \mathrm{~g}$ ) were prepared by evaporating water from the $\mathrm{WO}_{3}$ colloid solution, and then outgassed with helium for $2 \mathrm{hrs}$ at $200^{\circ} \mathrm{C}$ prior to the adsorption measurement. 
The Brunauer-Emmett-Teller (BET) method $^{37}$ was utilized to calculate the specific surface area. By using the Barrett-Joyner-Halenda (BJH) model $^{38}$, the pore size distributions were derived from the adsorption branches of isotherms. Proton nuclear magnetic resonance $\left({ }^{1} \mathrm{H}\right.$ NMR) spectra of the TPyP derivatives were recorded on an AVANCE DPX-400 (400 MHz) spectrophotometer (Bruker, USA) with tetramethylsilane (TMS) as the internal standard. MALDI-TOF mass spectra were measured on a Voyager DE PRO (Applied Biosystems, USA) using $\alpha$-cyano-4-hydroxycinnamic acid as a matrix. The TEM images of $\mathrm{WO}_{3}$ colloids before and after the addition of TPyP derivatives were measured with a JEM-2000EX II instrument (JEOL, Japan). The TEM samples were prepared by dropping the $\mathrm{WO}_{3}$ colloid sample solution onto a copper grid covered with a carbon film. The final TPyP derivatives concentration in the $\mathrm{WO}_{3}$ colloid sample solution was $2.0 \times 10^{-5} \mathrm{M}$. Each size distribution histogram of $\mathrm{WO}_{3}$ colloids was assessed by averaging the sizes of 100 particles directly from the TEM images and an optical particle-size analyzer (SALD-7100, Shimadzu, Japan). Static UV-visible spectra of TPyP derivatives in water and the $\mathrm{WO}_{3}$ colloid solution were obtained on a UV-1800 spectrometer (Shimadzu, Japan). $\mathrm{pH}$ values of the aqueous phase were conducted using a F-14 $\mathrm{pH}$ meter (HORIBA, Japan) equipped with a 6366-10D glass electrode. 


\section{RESULTS AND DISCUSSION}

\subsection{Preparation and Characterization.}

Colorless-transparent $\mathrm{WO}_{3}$ colloid solutions can be prepared according to previous work. ${ }^{26}$ The solutions thus obtained are of excellent colloidal stability (e.g., no precipitation for at least 1 month at room temperature) even though no stabilizing agent is used. A narrow size distribution of the $\mathrm{WO}_{3}$ particles would be required for sensitive and repeatable detection of TPyP derivatives' adsorption and aggregation phenomena on the $\mathrm{WO}_{3}$ surface. Therefore, we carefully optimized the conditions for preparation of the $\mathrm{WO}_{3}$ particles. The average particle size and size distribution in the as-prepared $\mathrm{WO}_{3}$ colloid solution were estimated by the combination of transmission electron microscope (TEM) and dynamic light scattering (DLS) techniques. Figure 1 shows the representative TEM image of as-prepared $\mathrm{WO}_{3}$ particles and their respective size distribution histograms from TEM and DLS results. As evident from the TEM image, the particles are roughly spherical in shape and well-dispersed with average particle size in the range of $16.8 \mathrm{~nm}$ $(n>100)$. Few particles tend to form irregular aggregates, which are seen as large particles in the image. Furthermore, DLS shows size distribution profiles of $\mathrm{WO}_{3}$ particles with diameters in the range 8-30 nm (see Figure 1(c)). DLS analyses determine hydrodynamic size of hydrated particles, whereas using TEM we can directly look at the particles in vacuo. Although the two techniques analyze particle sizes differently, the range of sizes derived from TEM and DLS results can be considered to be in good agreement. The nitrogen adsorption-desorption isotherms exhibited by the dried $\mathrm{WO}_{3}$ particles (Figure $\mathrm{S} 1(\mathrm{a})$ ) are very close to a type II isotherm based on Brunauer's classification, ${ }^{39}$ which is fairly typical of macroporous solids with pore diameters greater than $\sim 50 \mathrm{~nm}$. Indeed, the $\mathrm{BJH}$ pore-size distribution chart shows a uniform distribution, centered at ca. $50 \mathrm{~nm}$ (see Figure S1(b)). It should be noted that the pore diameter is larger than the particle sizes in above TEM images, suggesting the loose packing between the dried $\mathrm{WO}_{3}$ particles. This pore-size measurement result indicates that the TPyP derivatives used in this study (1.3-1.6 nm, see Figure 3(e)) are 
able to fully adsorb to the surface of the as-prepared $\mathrm{WO}_{3}$ particles in an aqueous system. The BET specific area of the dried $\mathrm{WO}_{3}$ particles is calculated to be $11.8 \mathrm{~m}^{2} / \mathrm{g}$.

Until now, syntheses of various tetrapyridyl porphyrin derivatives with substituents at the pyridyl$N$ position were reported. ${ }^{40}$ Following those procedures, syntheses of three $4 N$-alkyl substituted TPyP derivatives (TMPyP, TEPyP, and TPPyP; hereafter collectively referred to as "TPyP derivatives" including original TPyP) were carried out with TPyP and appropriately alkyl iodides in DMF. All TPyP derivatives were characterized by UV-Vis, ${ }^{1} \mathrm{H}-\mathrm{NMR}$, and MALDI-TOF/MS, all results were in good agreement with expected ones (see Experimental section). We studied the concentration dependence on the absorption spectra for the TPyP derivatives in water, as shown in Figure S2. The UV-vis spectra of the TPyP derivatives in water are dominated typically by two intense absorption: an intense Soret band (400-450 nm) and four weak Q-bands (500-650 $\mathrm{nm}$ region), which are typical for free-base porphyrins dyes. ${ }^{9}$ Interestingly, the peak positions of the TPyP derivatives in Soret- and Q-band were red-shifted with increasing the alkyl chain length at the pyridyl- $4 N$-position, implying that the energy gap between deeper levels and LUMO, and that between the HOMO and the LUMO, respectively, ${ }^{41}$ become smaller in the order: TPyP $>$ TMPyP $>$ TEPyP $>$ TPPyP. According to the calculated geometries of the porphyrin derivatives, the meso-aryl groups are not orthogonal to the porphyrin plane, but slightly tilted, ${ }^{42}$ allowing the meso-group to develop some conjugative interaction with the main porphyrin framework. Thus, in spite of the large dihedral angle between the plane of the pyridyl ring and the porphyrin $\pi$-system, conjugation exists to some extent and is also affected by inductive effect of the electron-donating alkyl substituents on the pyridyl ring. ${ }^{43}$ This conjugative interaction of the aromatic meso-substituents can explain the color shift observed for the TPyP derivatives, which might make the alkyl moiety at the pyridyl- $4 N$-position release an appreciable electron density to the porphyrin plane. The Lambert-Beer law was obeyed for all TPyP derivatives in the concentration range from $1 \times 10^{-6}$ to $1 \times 10^{-5} \mathrm{M}$ at the maximum absorption wavelength $\left(\lambda_{\max }: 419 \mathrm{~nm}\right.$ for TPyP, $421 \mathrm{~nm}$ for TMPyP, $423 \mathrm{~nm}$ for TEPyP, and $424 \mathrm{~nm}$ for TPPyP), as shown in the inset in Figure S2. They have a remarkably lower tendency 
toward aggregation in water. The absorbance maxima and molar absorption coefficient of the TPyP derivatives in water are listed in Table S1.

\subsection{Adsorption and Self-Aggregation of TPyP Derivatives on the $\mathrm{WO}_{3}$ Colloid Surface.}

Adsorption of dyes to various surfaces and then the formation of adsorbed dye aggregates have been well-known. ${ }^{44,45}$ The reactivities of the TPyP derivatives in the $\mathrm{WO}_{3}$ colloid solution were examined. As shown in Scheme 1, the structures for these four derivatives examined differ in terms of the length of the hydrocarbon chains substituted at the peripheral pyridyl- $4 N$ position. The differences are shown to exhibit profound differences in terms of the optical absorption data which characterize the reactivities of the TPyP derivatives on the $\mathrm{WO}_{3}$ colloid surface. As shown in Figure 2, the UV-vis spectra of all TPyP derivatives in water $\left(5.0 \times 10^{-6} \mathrm{M}, \mathrm{pH} 4\right)$ were affected by the $\mathrm{WO}_{3}$ addition. The $\mathrm{WO}_{3}$ concentration was varied from $1.0 \times 10^{-6}$ to $5.0 \times 10^{-4} \mathrm{M}$. Although the water-soluble porphyrin dyes are well-known to tend to aggregate in water, ${ }^{46,47}$ on the basis of the results described above section, the self-aggregation of the TPyP derivatives is negligible under this concentration $\left(5 \times 10^{-6} \mathrm{M}\right)$. Generally, in aqueous systems, metal oxide particles are hydrated and $-\mathrm{OH}$ groups cover completely their surface and the surface is neutral. The $-\mathrm{OH}$ sites on the surface of particles can react with $\mathrm{H}^{+}$or $\mathrm{OH}^{-}$ions from dissolved acids or bases, and positive $\left(-\mathrm{OH}_{2}{ }^{+}\right)$or negative $\left(-\mathrm{O}^{-}\right)$charges develop on the surface, and type of the reaction depends on $\mathrm{pH}$ of the solution. At a specific $\mathrm{pH}$, the positive and negative charge sites are in equal amounts; this represents the isoelectric point ( $\mathrm{p}$ ). At $\mathrm{pH}$ lower than $\mathrm{p} I$, the metal oxide surface is positively charged, while it has negative charge above

it. ${ }^{48}$ Because the $\mathrm{p} I$ value of tungsten(VI) oxide is $0.2-0.5,{ }^{49}$ the $\mathrm{WO}_{3}$ colloid surface is negatively charged in this aqueous solution $(\mathrm{pH}=4)$. Accordingly, the spectral changes obtained in this study would be explained in terms of the aggregation of the TPyP derivatives on the $\mathrm{WO}_{3}$ colloid surface via the electrostatic interaction between the cationic TPyP derivatives and the negatively charged $\mathrm{WO}_{3}$ colloid particles. Moreover, in all TPyP derivatives' spectra, the clear isosbestic points were observed during this titration 
experiment, indicating that the initial and final species were in equilibrium on the $\mathrm{WO}_{3}$ colloid surface. ${ }^{50}$ Considering the equilibrium between the monomer and aggregate of the TPyP derivative on the $\mathrm{WO}_{3}$ colloid surface, the adsorption constants onto the $\mathrm{WO}_{3}$ colloid surface $\left(K^{\prime}\right)$ and the aggregation constants on the $\mathrm{WO}_{3}$ colloid surface $\left(K^{\prime}{ }^{\prime}\right.$ gg $)$ can be defined as follows:

$$
\begin{aligned}
& \text { dye } \stackrel{K^{\prime}}{\rightleftharpoons}(\text { dye })_{\text {ad }} \\
& K^{\prime}=\frac{[\text { dye }]_{\mathrm{ad}}}{[\text { dye }]}, \\
& n(\text { dye })_{\text {ad }} \stackrel{K_{\text {agg }}^{\prime}}{\rightleftharpoons}\left\{\left(\text { dye }_{n}\right)\right\}_{\text {ad }} \\
& K_{\text {agg }}^{\prime}=\frac{\left[(\text { dye })_{n}\right]_{\mathrm{ad}}}{[\text { dye }]_{\mathrm{ad}}^{n}},
\end{aligned}
$$

where $[$ dye $]$ and $[\text { dye }]_{a d}$ are the concentration of the TPyP derivatives in the aqueous solution and on the $\mathrm{WO}_{3}$ nanocolloid surface, respectively. $\left[(\mathrm{dye})_{n}\right]_{\mathrm{ad}}$ represents the concentration of the aggregate of the TPyP derivatives on the $\mathrm{WO}_{3}$ colloid surface. The subscript or superscript " $n$ " is the apparent number of monomer in the unit aggregate addressed in an absorption spectral change. Assuming that the concentration of monomer TPyP derivative on the $\mathrm{WO}_{3}$ colloid surface is negligibly smaller than that of aggregate on the surface, the equilibrium concentration of the aggregate on the $\mathrm{WO}_{3}$ colloid surface was spectrometrically evaluated as the following;

$$
\left[(\text { dye })_{n}\right]_{\mathrm{ad}}=\frac{\left([\text { dye }]_{\mathrm{ini}}-[\text { dye }]\right) \cdot V}{n \cdot S}, \cdots
$$

where the subscript 'ini' denote initial concentration. $S$ and $V$ are the total surface area of the $\mathrm{WO}_{3}$ particles (calculated using BET specific area value) and the volume of the aqueous phase, respectively. Apparent isotherm plots of the TPyP derivatives in the $\mathrm{WO}_{3}$ colloid solution are shown in Figure 3. The isotherm behavior varied remarkably with the kind of the TPyP derivatives, indicating that the presence and kind of substituent groups at the peripheral pyridyl $-4 N$ positions affect the isotherm behavior. These plots are very 
similar to Langmuir isotherm ones. Classical Langmuir isotherm was based on the model of nonpenetrable boundary (surface/interface), where adsorbates can substitute only molecules of one solvent and not then interact with each other. However, the TPyP derivatives strongly aggregate on the $\mathrm{WO}_{3}$ colloid surface; therefore, this classical isotherm model is not directly applicable in this case. In order to analyze the TPyP derivatives' adsorption and aggregation behaviors in the $\mathrm{WO}_{3}$ colloid solution, we combined Langmuir isotherm equation, Eqs (1) and (2), to give

$$
\left[(\text { dye })_{n}\right]_{\mathrm{ad}}=\frac{K_{\mathrm{agg}}^{\prime}\left(a K^{\prime}[\text { dye }]\right)^{n}}{\left(a+K^{\prime}[\text { dye }]\right)^{n}}
$$

Herein, $a$ refers to the saturated concentration on the $\mathrm{WO}_{3}$ colloid surface. As shown in Figure 3 , the stoichiometric analysis of the experimental data by using Eq.(4) suggested the aggregation of the dimer $(n=$ 2) of all TPyP derivatives on the $\mathrm{WO}_{3}$ colloid surface. It means that the aggregate formed on the $\mathrm{WO}_{3}$ colloid surface must include two TPyP derivative units as a minimum number. The obtained adsorption and the aggregation parameters of the TPyP derivatives are summarized in Table 1 . The effect of the substituent(s) at peripheral pyridyl- $4 N$ positions on the adsorption and aggregation behaviors of the TPyP derivatives on the $\mathrm{WO}_{3}$ colloid surface is obvious. The $K^{\prime}$ values are increased in the order of TPPyP $<$ TEPyP $<$ TMPyP $<$ TPyP. The adsorptivity of the TPyP derivatives would be likely reduced due to steric hindrance of the peripheral hydrocarbon chains (methyl, ethyl, and $n$-propyl) at the pyridyl- $4 N$ positions. On the other hand, the $K_{\text {agg }}$ values are increased in the order of TPyP $<$ TMPyP $<$ TEPyP $<$ TPPyP. Interestingly, this is the opposite order of $K^{\prime}$ values. The TPyP derivatives solved in water $(\mathrm{pH}=4)$ have positive charges at the peripheral pyridyl groups, so they repel each other, at least at short range. As a result, they exist in a monomer form. When the cationic TPyP derivatives are adsorbed on the negatively charged $\mathrm{WO}_{3}$ surface, some of the peripheral pyridyl groups are electrostatically neutralized and the ones would eventually attract each other both through $\pi-\pi$ stacking between porphyrin planes and through van der Waals force interaction between hydrocarbon chains at the pyridyl- $4 N$ position. This finding demonstrates that the 
hydrophilic/hydrophobic and steric balance of the substituent groups at the peripheral pyridyl-4N positions have dramatic effect upon the adsorption and aggregation behaviors of the TPyP derivatives on the $\mathrm{WO}_{3}$ colloid surface. Moreover, in order to elucidate the detail adsorption mechanism of the TPyP derivatives onto the $\mathrm{WO}_{3}$ colloid surface, we investigated the influence of ionic strength on the isotherm under a constant TPyP derivative concentration. As found from Figure 3 and Table 1, the adsorptivity of the TPyP derivatives onto the $\mathrm{WO}_{3}$ colloid surface was decreased with an increase in the sodium sulfate concentration. Such a tendency clearly indicates that the electrostatic interaction between cationic TPyP derivative molecules and negative charged $\mathrm{WO}_{3}$ colloid surface contributes to the adsorption behavior of the TPyP derivatives on the $\mathrm{WO}_{3}$ colloid surface. The $K^{\prime}$ and $K^{\prime}$ agg values calculated from Eq. (4) allow us to generate the pure monomer and dimer spectra in the $\mathrm{WO}_{3}$ colloid solution. The resolved monomer and dimer spectra of four TPyP derivatives are shown in Figure 4. In the Soret region (from 380 to $470 \mathrm{~nm}$ ), the pure dimer spectra of the TPyP derivatives mainly are constructed from two components which appear on the shorter and longer wavelength side of the monomer Soret band. This Soret band-splitting may be very important in understanding a nanostructure of the aggregate of the TPyP derivatives adsorbed on the $\mathrm{WO}_{3}$ colloid surface, and potentially aid in development of novel self-assembled nanoscale architecture on metal oxide as nanotemplates or supports. Details of the information on the TPyP derivatives' aggregates formed on the $\mathrm{WO}_{3}$ colloid surface will be discussed in a later section.

Figure 5 shows the typical TEM micrograph, the corresponding histogram, and the DLS result of $\mathrm{WO}_{3}$ colloids in the presence of TPyP. In contrast to the monodisperse feature for the $\mathrm{WO}_{3}$ colloid solution in the absence of the TPyP derivatives as mentioned above (see Figure 1A), the sample taken from the solution after adding TPyP reveal features of agglomerated $\mathrm{WO}_{3}$ particles (Figure 5(a)). From the corresponding size distribution histogram ( $>100$ particles from TEM images), it is found that the $\mathrm{WO}_{3}$ colloids have an average diameter of $18.2 \mathrm{~nm}$, indicating that the amount of large $\mathrm{WO}_{3}$ colloid particles is increased slightly after the addition of TPyP. On the other hand, the $\mathrm{WO}_{3}$ colloid solution in the presence of 
TPyP shows in DLS clearly a bimodal size distribution of particles (see Figure 5(c)). It can be seen that the particle size of the larger population in the $\mathrm{TPy} / \mathrm{WO}_{3}$ aqueous system is akin to the agglomeration size observed in TEM image. From the obtained results of TEM and DLS measurements, surface charge neutralization, which accompanies the adsorption of the TPyP derivative on the $\mathrm{WO}_{3}$ colloids, would induce such an agglomeration. The formation of $\mathrm{WO}_{3}$ particles' agglomeration further supports the explanations for the above absorption spectral changes.

\subsection{Surface Aggregate Structure Deduced from Kasha's Exciton Coupling Theory and Langmuir}

\section{Model Analysis.}

Self-dimerization of TPyP derivatives adsorbed on the $\mathrm{WO}_{3}$ colloid surface can be followed by UV-Vis absorption spectroscopy and modified Langmuir monolayer model. Using the observed saturated concentration $(a)$ values of TPyP derivatives, the occupied area per molecule on the $\mathrm{WO}_{3}$ colloid surface was calculated to be $142,178,198$, and $219 \AA^{2} /$ molecule for TPyP, TMPyP, TEPyP, and TPPyP, respectively. Because these experimental occupied area values are $c a .10 \%$ smaller than the cross-sectional area values of the TPyP derivatives lying flat-on (see area A in Figure 3(e)) and $c a .110 \%$ larger than the ones lying edgeon (see area B in Figure 3(e)), the TPyP derivatives are somewhat tilted with respect to the $\mathrm{WO}_{3}$ surface. Since the $\mathrm{WO}_{3}$ colloid particles used in this study are close to a spherical shape with radius $R$, the adsorption onto curved surfaces should be considered. Thereupon, we hypothesize the probable model for adsorption of the TPyP derivatives on the $\mathrm{WO}_{3}$ colloid surface, as shown in Scheme $2 .{ }^{51-53}$ Taking into account that the curvature radius $R$ of $\mathrm{WO}_{3}$ colloid particles nearly equals to $7.9 \mathrm{~nm}$ (from TEM image), we predicted the molecular area (per TPyP derivative) as follows:

$$
\text { occupied molecular area } \approx 2 R^{2} \tan ^{-1}\left(\frac{l}{2 R}\right) \tan ^{-1}\left(\frac{l \sin \phi}{(l \sin \phi+R) \tan \phi}\right),
$$


where $l$ and $\phi$ are the length of the box approximating TPyP derivative molecule calculated from CPK molecular model (see Figure 3(e)) and the tilting angle of the porphyrin plane from the tangent line to a $\mathrm{WO}_{3}$ particle surface, respectively. The $\phi$ values of the TPyP derivatives were estimated to be $29.0^{\circ}, 22.6^{\circ}, 21.7^{\circ}$, and $20.7^{\circ}$ for TPyP, TMPyP, TEPyP, and TPPyP, respectively. It is noteworthy, for metal-oxide surface chemistry, therefore, that the adsorption configuration of a porphyrin dye adlayer is variable depending on the presence and kind of substituent groups at the peripheral pyridyl- $4 N$ positions.

It is well-known that molecular aggregation drastically modifies the absorption characteristics (spectral shifts, band broadening, and sharpening) of the dyes. ${ }^{54,55}$ The simple exciton theory ${ }^{56,57}$, a quantum mechanics method considering the electrostatic interactions between the dipole moments of monomeric units, can be here applied to interpret the spectral changes. It predicts a different electronic energy diagram and photophysical behavior of aggregates depending on the geometrical distribution of the monomer units. This theory suggests a two excited-state splitting of the monomer electronic transition for the aggregate, with multiplicities of singlet and triplet. The energy gap and the transition probabilities from the ground state to these excited states depend on the relative orientation of the transition moment vectors of the monomeric units in the aggregate. For arrangements where the transition moment vectors of the monomeric units are parallel, two specific cases can be considered taking into account the angle between the direction of the transition dipole moments and the line linking the molecular centers (slipping angle $\theta$, see Scheme 3(a)). If slipping angle $\theta$ approaches $90^{\circ}$, the monomers form the so-called $H$-type (face-to-face fashion) aggregate, and the allowed transition produces a shift of the absorption band to higher energies ( $H$-band). This is due to the fact that upon splitting the energy of the singlet excited state is higher than that of the triplet excited state, singlet to singlet transition being allowed. On the other hand, if slipping angle $\theta$ approaches $0^{\circ}$, the monomers form the so-called $J$-type (head-to-tail fashion) aggregate, the allowed transition produces a shift of the absorption band to lower energies ( $J$-band), since the singlet excited state has less energy than the 
triplet excited state. Transition dipole coupling within an aggregate of $N$ dye molecules leads to perturbed excited electronic states with energies and transition moments given by

$$
E=E_{\text {mono }} \pm \Delta E
$$

where $E_{\text {mono }}$ is the energy of the excited state of the monomer, relative to the ground state, and $\Delta E$ is the exciton coupling matrix element. According to the extended exciton coupling approximation, this is given by

$$
\begin{aligned}
& \Delta E=2 \sum_{i \neq j}^{N} J_{i j}, \cdots \cdots \cdots \\
& J_{i j}=\frac{|\mu|^{2}}{r_{i j}^{3} h c}\left(1-3 \cos ^{2} \theta\right)
\end{aligned}
$$

where $J_{i j}$ is the interaction integral given by summing all Coulomb interactions of translationally equivalent transition dipoles, $N$ the aforementioned coherent aggregation number, $\mu$ the magnitude of the monomer transition moment, $h$ Planck's constant $\left(6.63 \times 10^{-34} \mathrm{~J} \mathrm{sec}\right), c$ the speed of light in vacuum $\left(3.0 \times 10^{8} \mathrm{~m} / \mathrm{sec}\right)$, and $r_{i j}$ the distance between the $i$-th dye molecule and the $j$-th other dye molecule. It is well-known that the Soret band of porphyrin has two perpendicular transition dipole moments of the almost same magnitude $\left(\mathrm{B}_{x}\right.$ and $\mathrm{B}_{y}$, see Scheme 3(b)). Accordingly, coupling of both $\mathrm{B}_{x}$ and $\mathrm{B}_{y}$ components in the porphyrin plane must be considered. In the following analysis, we assume that the two blue- and red-shifted Soret bands $(H$ - and $J$ band, respectively) arise from the same porphyrin species, which we postulate to be a dimer. To account for the Soret band splitting of TPyP derivatives in the $\mathrm{WO}_{3}$ colloid solution, we tentatively propose a brick-stone dimer structure, as shown in Scheme 3(b). Coupling of the transition moments along the $x$-axis (parallel to the aggregate long axis) leads to a red-shifted exciton state ( $J$-band), while coupling of the $y$-axis transition moments (perpendicular to the aggregate long axis) results in a blue-shifted transition ( $H$-band). Indeed, Ohno et al. concluded from theory and experiments that an aggregate of anionic porphyrin compound [5,10,15,20-tetrakis(4-sulfophenyl)porphyrin (TPPS)] had both $H$ - and $J$-bands at 420 and $491 \mathrm{~nm}$, respectively, where the monomeric TPPS had an absorption maximum at $439 \mathrm{~nm}$ in aqueous solutions. ${ }^{58}$ As mentioned above section, the mathematically resolved pure spectra of TPyP derivatives' dimer formed on the 
$\mathrm{WO}_{3}$ colloid surface have a main $J$-band that is red-shifted relative to the monomer Soret band which accompanies a small blue-shifted $H$-band. Upon the titration of $\mathrm{WO}_{3}$ colloid solution, we found that the blueand red-shifted Soret bands of TPyP derivatives evolve synchronously, which also suggests that they are associated with the same aggregate species. From the spectral peak positions and splitting of the $H$ - and $J$ bands (409 and $445 \mathrm{~nm}$ for TPyP, 410 and $436 \mathrm{~nm}$ for TMPyP, 412 and $438 \mathrm{~nm}$ for TEPyP, 414 and $439 \mathrm{~nm}$ for TPPyP, respectively), we put $N$ number equal to 2 (dimer) in Eq.(7) and predicted the couplings of $H$ - and $J$-band ( $\Delta E_{H}$ and $\Delta E_{J}$, respectively) as follows:

$$
\begin{aligned}
& \Delta E_{H}=\frac{2|\mu|^{2}}{r^{3} h c}, \cdots \ldots \ldots \ldots \ldots . . \\
& \Delta E_{J}=\frac{2|\mu|^{2}}{r^{3} h c}\left(1-3 \cos ^{2} \theta_{x}\right), \\
& r=\frac{d}{\sin \theta_{x}}, \cdots \ldots \ldots \ldots \ldots . .
\end{aligned}
$$

where $r$ is the distance between neighboring molecules, $d$ is vertical distance between the porphyrin planes, $\theta_{x}$ is the slipping angle between the $x$-axis transition moment and the line connecting the molecular centers in the brick-stone dimer model of the TPyP derivatives. Equations (9) and (10) neglect disorder, non-nearest neighbor couplings, and curvature $\mathrm{WO}_{3}$ colloid surface. On attempting to apply these simple equations to the dimer which forms on the $\mathrm{WO}_{3}$ colloid surface, we explain the aggregate geometry in detail. The above equations are satisfied by taking $\theta_{x}=27.1^{\circ}$ and $d=3.63 \AA$ for TPyP, $21.3^{\circ}$ and $3.67 \AA$ for TMPyP, $20.2^{\circ}$ and $3.59 \AA$ for TEPyP, and $19.3^{\circ}$ and $3.71 \AA$ for TPPyP. Since the $\pi-\pi$ stacking distance between neighboring porphyrin ligands in single crystals of tetrakis(phenyl)porphyrin (TPP) is $3.5 \AA$ according to single crystal Xray diffraction analysis, ${ }^{46}$ the calculated $d$ values for the TPyP derivatives seem reasonable. Interestingly, the calculated $\theta_{x}$ value of each TPyP derivative is almost same with the $\phi$ one, although $\theta_{x}$ is a little smaller than $\phi$. This difference may be due to an over/underestimate of the $\mathrm{WO}_{3}$ particle size in the TPyP derivative/ $\mathrm{WO}_{3}$ adsorption model described in Scheme 2, because the $\mathrm{WO}_{3}$ particles used in this study have a size 
distribution. Anyhow, this joint evidence provided by Langmuir adsorption model (tilting angle: $\phi$ ) and exciton coupling theory (slipping angle: $\theta_{x}$ ) supported that the $J$-dimer geometry of the TPyP derivatives adsorbed on the $\mathrm{WO}_{3}$ colloid surface was controlled by the substituents at the peripheral pyridyl-4N position. Of course, we understand that this is only a speculation, and further studies of other TPyP derivatives and related compounds will be important. Work along these lines is in progress. 


\section{CONCLUSION}

In the present study, the adsorption and aggregation behaviors of the TPyP derivatives with different substituents at the peripheral pyridyl-4N position, containing 5,10,15,20-tetrakis(4pyridyl)porphyrin $\quad$ (TPyP), 5,10,15,20-tetrakis( $N$-methyl-4-pyridyl)porphyrin $\quad$ (TMPyP), 5,10,15,20tetrakis( $N$-ethyl-4-pyridyl)porphyrin (TEPyP), and 5,10,15,20-tetrakis( $N$ - $n$-propyl-4-pyridyl)porphyrin (TPPyP), in the $\mathrm{WO}_{3}$ colloid aqueous solution were spectrophotometrically investigated. All cationic TPyP derivatives are adsorbed onto the negatively charged $\mathrm{WO}_{3}$ colloid surface by the electrostatic interaction, and eventually form $J$-type dimers aligned in the head-to-tail fashion. Although the hydrocarbon chains substituted at the peripheral pyridyl- $4 N$ position enhance the dimerization of the TPyP derivatives on the $\mathrm{WO}_{3}$ colloid surface probably due to van der Waals attractive interaction, the adsorption of the derivatives onto the surface is suppressed by the substituents because of steric repulsive interaction. We have also shown, in this study, that the $J$-dimer conformation of the TPyP derivatives adsorbed on the $\mathrm{WO}_{3}$ colloid particle surface, which have been well supported by multiple experimental characterization techniques (exciton coupling theory and Langmuir adsorption model), is strongly dependent on the presence and difference of peripheral substituents. Hence, since the surface/interface in organic/inorganic nanocomposites is the region that facilitates the transport of energy (photon and electron) across the material, the adsorption/aggregation morphology of organic dyes on the metal oxide surface will play a crucial role in the extent of property enhancement that we can expect. 


\section{ACKNOWLEDGEMENT}

This study was partially supported by the Scientific Research of the Grant-in-Aid for Young Scientists (B) (No. 24750069) from Japan Society for the Promotion of Science (JSPS). TEM measurements documented in this study were performed at the Innovation Center, Yamaguchi University.

\section{SUPPORTING INFORMATION}

Nitrogen adsorption isotherm for the dried $\mathrm{WO}_{3}$ colloid; Concentration- and pH-dependence of UV-Vis absorption spectra of the TPyP derivatives in water; Additional spectral data. This information is available free of charge via the Internet at http://pubs.acs.org/. 


\section{REFERENCES}

[1] Kauffman, S.A.; The Origins of Order: Self-Organization and Selection in Evolution, Oxford University Press, USA (1993).

[2] Fenske, T.; Korth, H.-G.; Mohr, A.; Schmuck, C.; Chem. Eur. J., 2012, 18, 738-755.

[3] Astruc, D.; Boisselier, E.; Ornelas, C.; Chem. Rev., 2010, 110, 1857-1959.

[4] Whitesides, G. M.; Grzybowski, B.; Science, 2002, 295, 2418-2421.

[5] Castriciano, M.A.; Romeo, A.; Luca, G.D.; Villari, V.; Scolaro, L.M.; Micali, N.; J. Am. Chem. Soc., 2011, 133, 765-767.

[6] Arai, Y.; Segawa, H.; J. Phys. Chem. B, 2012, 116, 13575-13581.

[7] Sandanayaka, A.S.D.; Murakami, T.; Hasobe, T.; J. Phys. Chem. C, 2009, 113, 18369-18378.

[8] Yoshimoto, S.; Itaya, K.; J. Porphyrins Phthalocyanines, 2007, 11, 313-333.

[9] Gouterman, M.; Rentzepis, P.M.; Straub, K.D.; (eds), Porphyrins: Excited States and Dynamics, American Chemical Society, USA (1987).

[10] Milgrom. L.R.; The Colours of Life: An Introduction to the Chemistry of Porphyrins and Related Compounds, Oxford University Press, USA (1997).

[11] Fan, D.; Xia, X.; Ma, H.; Du, B.; Wei, Q.; J. Colloid Interf. Sci., 2013, 402, 146-150.

[12] Guo, P.; Chen, P.; Liu, M.; Langmuir, 2012, 28, 15482-15490.

[13] P. Guo, P. Chen, W. Ma, M. Liu, J. Mater. Chem., 2012, 22, 20243-20249.

[14] Wang, J.; Liu, C.; Ding, D.; Zeng, L.; Cao, Q.; Zhang, H.; Zhao, H.; Li, X.; Xiang, K.; He, Y.; Wang, G.; New J. Chem., 2011,35, 1424-1432.

[15] Pastore, M.; Angelis, F.D.; ACS Nano, 2010, 4, 556-562.

[16] Hagfeldt, A.; Boschloo, G.; Sun, L.; Kloo, L.; Pettersson, H.; Chem. Rev., 2010, 110, 6595-6663.

[17] Galoppini, E.; Coord. Chem. Rev., 2004, 248, 1283-1297.

[18] Ye, S.; Kathiravan, A.; Hayashi, H.; Tong, Y.; Infahsaeng, Y.; Chabera, P.; Pascher, T.; Yartsev, A.P.; Isoda, S.; Imahori, H.; Sundström, V.; J. Phys. Chem. C, 2013, 117, 6066-6080.

[19] Waltera, M.G.; Rudine, A.B.; Wamser, C.C.; J. Porphyrins Phthalocyanines, 2010, 14, 759-792.

[20] Rochford, J.; Chu, D.; Hagfeldt, A.; Galoppini, E.; J. Am. Chem. Soc., 2007, 129, 4655-4665.

[21] Luo, L.; Lo, C.-F.; Lin, C.-Y.; Chang, I-J.; Diau, E.W.-G.; J. Phys. Chem. B, 2006, 110, 410-419.

[22] Zhang, Q.; Cao, G.; Nano Today, 2011, 6, 91-109.

[23] Durrant, J.R.; Haque, S.A.; Palomares, E.; Coord. Chem. Rev., 2004, 248, 1247-1257.

[24] Clifford, J.N.; Palomares, E.; Nazeeruddin, M.K.; Grätzel, M.; Nelson, J.; Li, X.; Long, N.J.; Durrant, J.R.; J. Am. Chem. Soc., 2004, 126, 5225-5233. 
[25] Adachi, K.; Tanaka, S.; Yamazaki, S.; Takechi, H.; Tsukahara, S.; Watarai, H.; New J. Chem., 2012, $36,2167-2170$.

[26] Adachi, K.; Mita, T.; Yamate, T.; Yamazaki, S.; Takechi, H.; Watarai, H.; Langmuir, 2010, 26, 117 125.

[27] Eckenrode, H.M.; Jen, S.-H.; Han, J.; Yeh, A.-G.; Dai, H.-L.; J. Phys. Chem. B, 2005, 109, 46464653.

[28] Yamazaki, S.; Yamate, T.; Adachi, K.; Appl. Catal. A-Gen., 2013, 454, 30-36.

[29] Esposito, D.V.; Forest, R.V.; Chang, Y.; Gaillard, N.; McCandless, B.E.; Hou, S.; Lee, K.H.; Birkmire, R.W.; Chen, J.G.; Energy Environ. Sci., 2012, 5, 9091-9099.

[30] Seabold, J.A.; Choi, K.-S.; Chem. Mater., 2011, 23, 1105-1112.

[31] Gao, T.; Jelle, B.P.; J. Phys. Chem. C, 2013, 117, 13753-13761.

[32] Baetens, R.; Jelle, B.P.; Gustavsen, A.; Sol. Energ. Mat. Sol. C., 2010, 94, 87-105.

[33] Tanaka, S.; Adachi, K.; Yamazaki, S.; Analyst, 2013, 138, 2536-2539.

[34] He, Y.; Wu, Z.; Fu, L.; Li, C.; Miao, Y.; Cao, L.; Fan, H.; Zou, B.; Chem. Mater., 2003, 15, 40394045.

[35] Hambright, P.; Batinić-Haberle, I.; Spasojević, I.; J. Porphyrins Phthalocyanines, 2003, 7, 139-146.

[36] Batinić-Haberle, I.; Spasojević, I.; Stevens, R.D.; Hambright, P.; Fridovich, I.; J. Chem. Soc., Dalton Trans., 2002, 2689-2696.

[37] Brunauer, S.; Emmet, P.H.; Teller, E.; J. Am. Chem. Soc., 1938, 60, 309-319.

[38] Barrett, E.P.; Joyner, L.G.; Halenda, P.P.; J. Am. Chem. Soc., 1951, 73, 373-380.

[39] Brunauer, S.; The Adsorption of Gases and Vapors, Oxford Univ. Press, UK, 1944.

[40] Kadish, K.; Smith, K.M.; Guilard. R.; (eds), The Porphyrin Handbook: Vol. 3: Inorganic, organometallic and coordination chemistry, Academic Press, USA (1999).

[41] Gouterman, M.; J. Mol. Spectrosc., 1961, 6, 138-163.

[42] Kadish, K.; Smith, K.M.; Guilard. R.; (eds), The Porphyrin Handbook: Vol. 7: Theoretical and Physical Characterization, Academic Press, USA (1999).

[43] O’Reilly, R.J.; Karton, A.; Radom, L.; J. Phys. Chem. A, 2011, 115, 5496-5504.

[44] del Monte, F.; Levy, D.; J. Phys. Chem. B, 1998, 102, 8036-8041.

[45] Lee, P.C.; Meisel, D.; J. Phys. Chem., 1982, 86, 3391-3395.

[46] Kano, K.; Fukuda, K.; Wakami, H.; Nishiyabu, R.; Pasternack, R.F.; J. Am. Chem. Soc., 2000, 122, 7494-7502.

[47] Kano, K.; Minamizono, H.; Kitae, T.; Negi, S.; J. Phys. Chem. A, 1997, 101, 6118-6124. 
[48] Adamson, A.W.; Gast, A.P.; Physical Chemistry of Surfaces (6 ${ }^{\text {th }}$ edition), Wiley-Interscience, USA (1997)

[49] Parks, G.A.; Chem. Rev., 1965, 65, 177-198.

[50] Conners, K.A.; Binding Constants, John Wiley \& Sons, USA (1987).

[51] Pedrosa, J.-M.; Teresa, M.; Romero, M.; Camacho, L.; J. Phys. Chem. B, 2002, 106, 2583-2591.

[52] Moriya, Y.; Hayashi, K.; Nakata, S.; Ogawa, N.; Anal. Sci., 2001, 17(Suppl.), i1253-i1256.

[53] Miyata, A.; Unuma, Y.; Higashigaki, Y.; Bull. Chem. Soc. Jpn., 1993, 66, 993-998.

[54] Kobayashi, T.; (ed), J-aggregates, World Scientific Publishing: Singapore (1996).

[55] Kobayashi, T.; (ed), J-aggregates Vol. 2, World Scientific Publishing: Singapore (2012).

[56] El-Sayed, M.A.; Barbara, P.; Nicol, M.; J. Phys. Chem., 1991, 95, 10215-10220.

[57] McRae, E.G.; Kasha, M.; J. Chem. Phys. 1958, 28, 721-722.

[58] Ohno, O.; Kaizu, Y.; Kobayashi, H.; J. Chem. Phys., 1993, 99, 4128-4139. 


\section{Figure Captions}

Figure 1 (a) TEM image and corresponding particle size distribution histogram as experimentally determined by (b) TEM images and (c) DLC measurements for the as-prepared $\mathrm{WO}_{3}$ colloid particles.

Figure 2 Change of UV-visible absorption spectra of (a) TPyP, (b) TMPyP, (c) TEPyP, and (d) TPPyP aqueous solution as a function of added $\mathrm{WO}_{3}$ colloid. Concentration conditions: $[\mathrm{dye}]=1.0 \times 10^{-6}$ $\mathrm{M} ;\left[\mathrm{Na}_{2} \mathrm{SO}_{4}\right]=3.3 \times 10^{-3} \mathrm{M} ; \mathrm{pH} 4$, molar ratios $\left(\left[\mathrm{WO}_{3}\right] /[\right.$ dye $]$ ) as follows: (A) 0, (B) 5, (C) 10, (D) 20, (E) 40, (F) 60, (G) 100. The arrows indicate the direction of the absorbance changes, as the $\mathrm{WO}_{3}$ colloid concentration is increased.

Figure 3 Adsorption isotherms of (a) TPyP, (b) TMPyP, (c) TEPyP, and (d) TPPyP on the $\mathrm{WO}_{3}$ colloid surface. Concentration conditions: $[$ dye $]=1.0 \times 10^{-6} \mathrm{M} ;\left[\mathrm{WO}_{3}\right]=1.0 \times 10^{-6} \sim 1.0 \times 10^{-3} \mathrm{M} ;\left[\mathrm{Na}_{2} \mathrm{SO}_{4}\right]$ $=3.3 \times 10^{-3} \mathrm{M}$ (open square), $3.3 \times 10^{-2} \mathrm{M}$ (open triangle); $\mathrm{pH} 4$. The solid lines are fitted by Eq. (6). (e) Box approximating TPyP derivative molecule. Areas for each face A (flat-on) and B (edge-on) were determined from the CPK model structure.

Figure 4 Resolved monomer and dimer spectra of (a) TPyP, (b) TMPyP, (c) TEPyP, and (d) TPPyP in the $\mathrm{WO}_{3}$ colloid solution at $25^{\circ} \mathrm{C}$.

Figure 5 (a) TEM image and corresponding particle size distribution histogram as experimentally determined by (b) TEM images and (c) DLC measurements for the $\mathrm{WO}_{3}$ colloid particles with $2.0 \times 10^{-5}$ M TPyP. 


\section{Scheme titles}

Scheme 1 Molecular structure of cationic porphyrin dyes used in this study.

Scheme 2 Schematic illustration of proposed model for adsorption of the TPyP derivatives onto the $\mathrm{WO}_{3}$ particle with radius $R$. The rectangles represent TPyP derivatives.

Scheme 3 (a) Orientation dependence in exciton coupling between two chromophores (ellipses) and their electric dipoles (arrow in ellipse). The solid and dashed arrows from ground states to excited states represent allowed and forbidden transitions, respectively. (b) Schematic illustration of red-shifted ( $J$-band) and blue-shifted ( $H$-band) exciton transitions from coupling of two kinds of transition dipole moments $\left(\mathrm{B}_{x}\right.$ and $\left.\mathrm{B}_{y}\right)$ which are parallel and perpendicular, respectively, to the slipping direction (along the $x$-axis) of aggregate. The squares represent the ТPyP derivatives. 
Figure 1
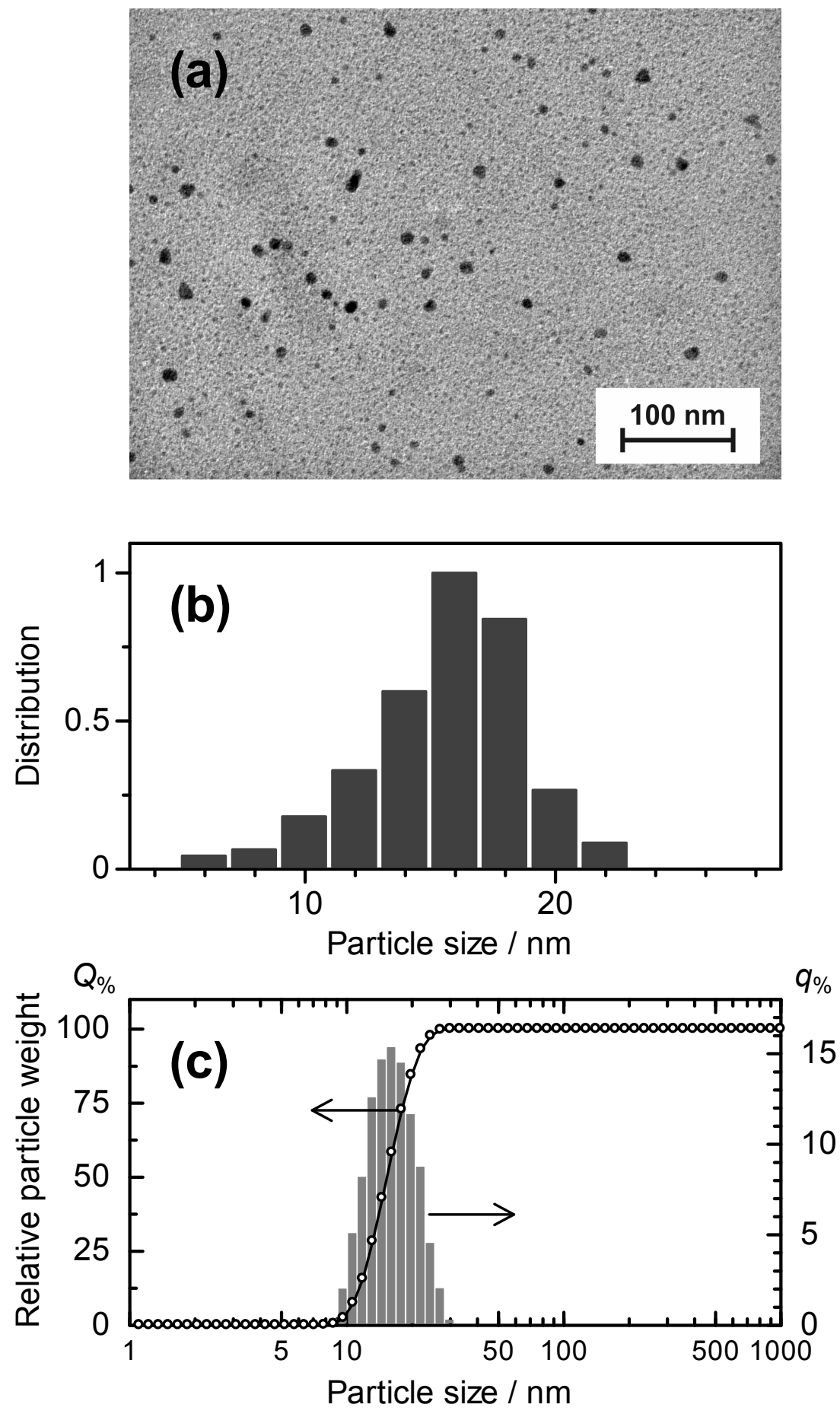
Figure 2

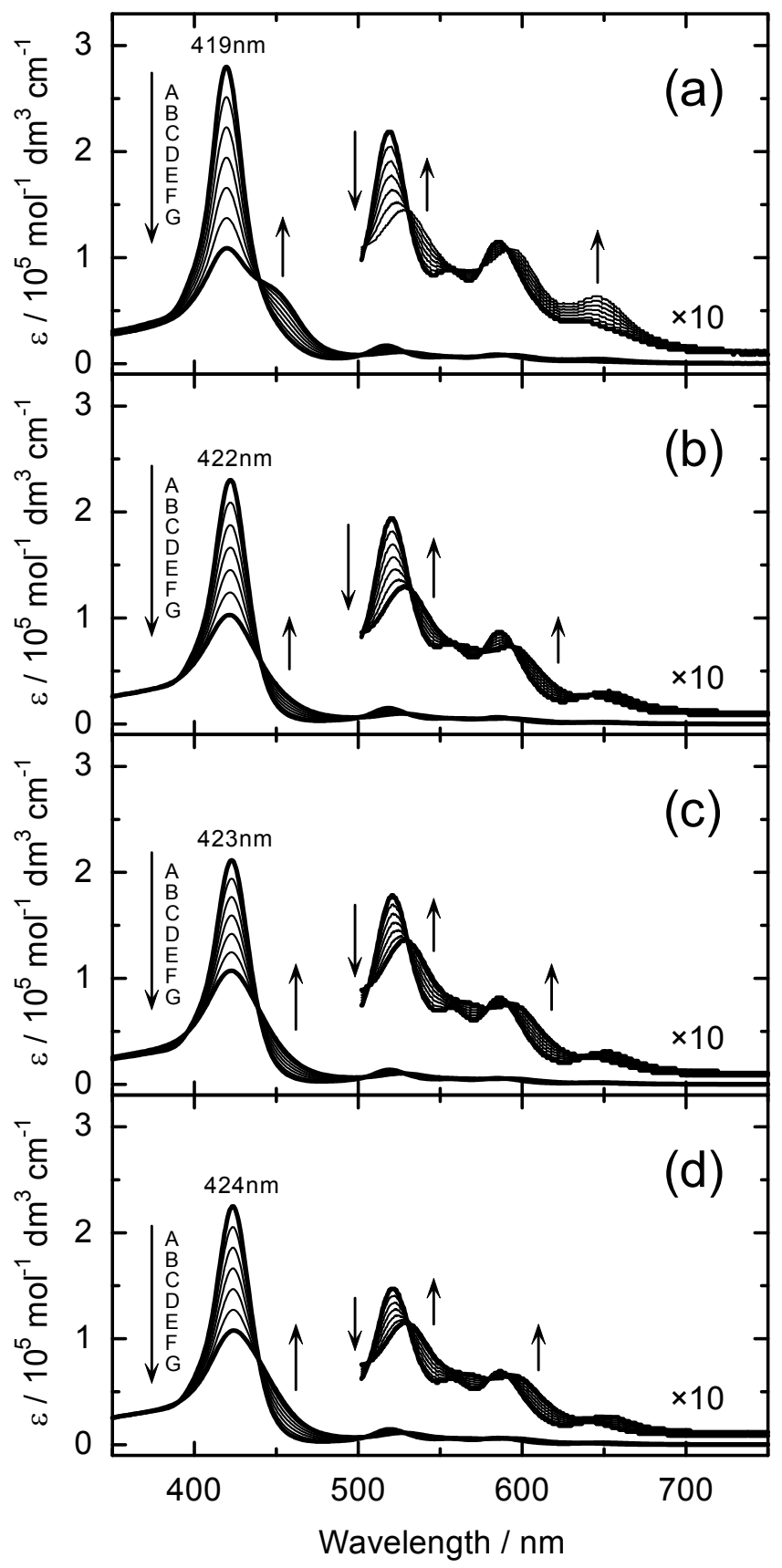


Figure 3
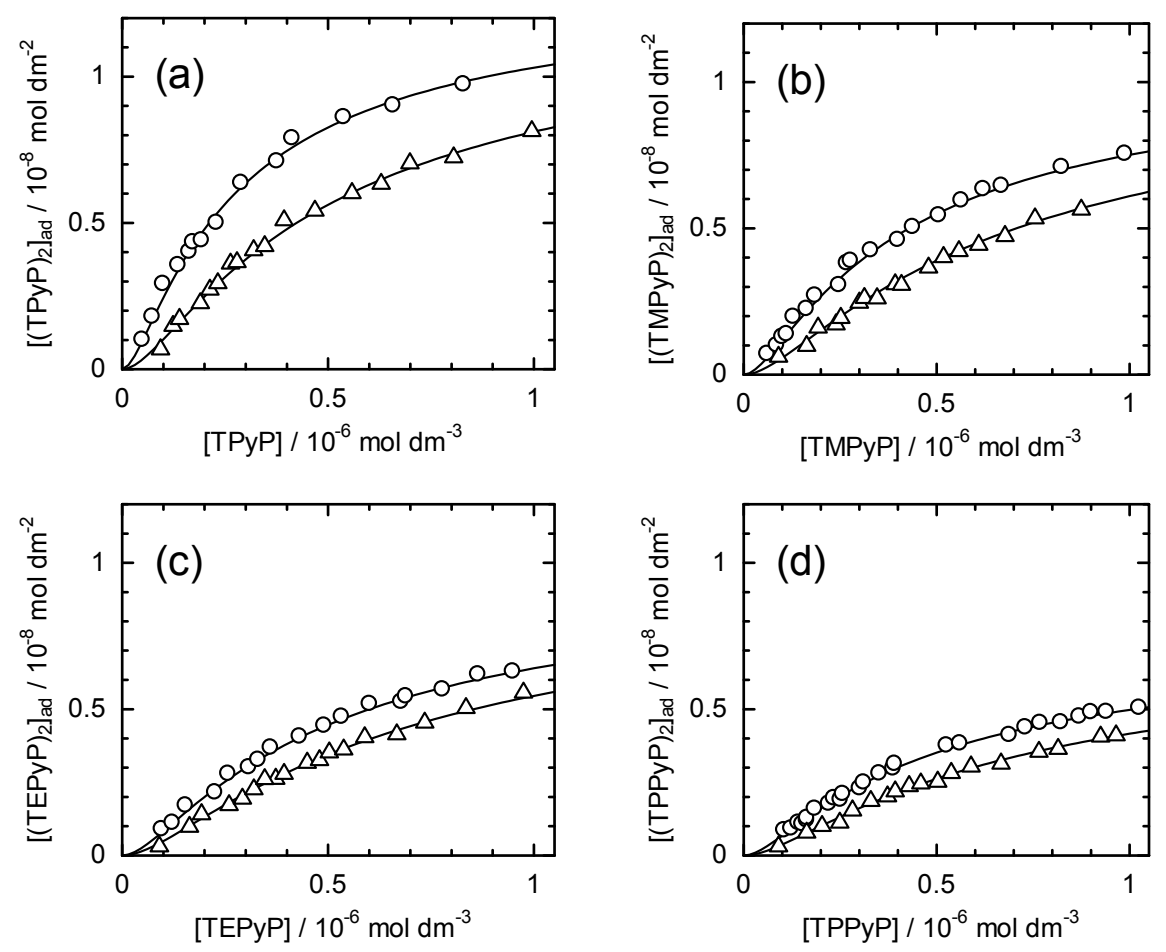

(e)

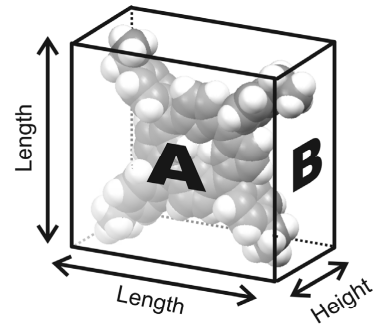

Length Height Area A Area B $\begin{array}{lllll}\text { TPyP } & 12.5 \AA & 5.6 \AA & 157 \AA^{2} & 70 \AA^{2}\end{array}$

$\begin{array}{lllll}\text { TMPyP } & 13.8 \AA & 5.6 \AA & 191 \AA^{2} \quad 77 \AA^{2}\end{array}$

TEPyP $\quad 14.5 \AA \quad 5.6 \AA \quad 210 \AA^{2} \quad \mathbf{8 1} \AA^{2}$

$\begin{array}{lllll}\text { TPPyP } & 15.5 \AA & 5.7 \AA & 240 \AA^{2} & 88\end{array}$ 
Figure 4

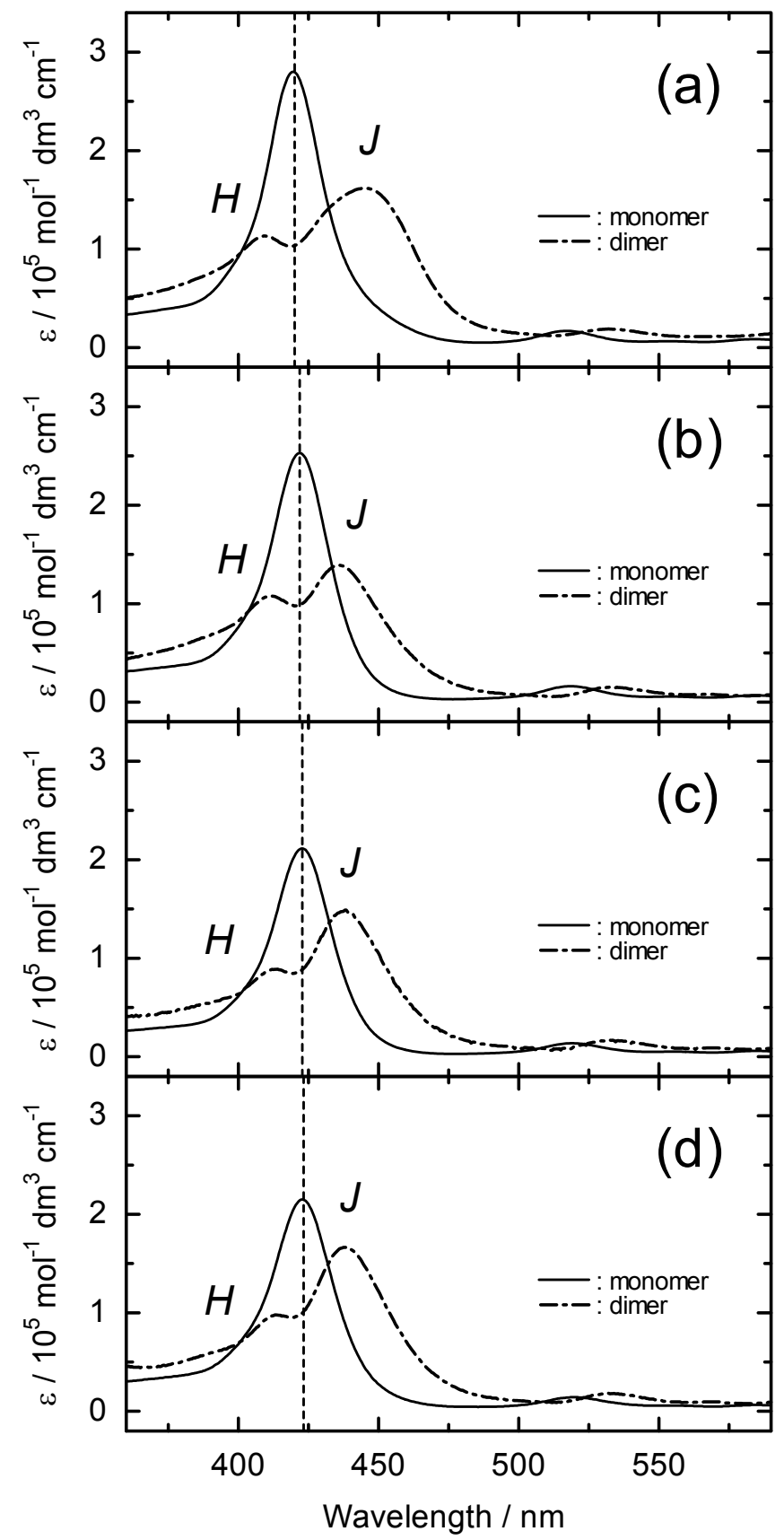


Figure 5
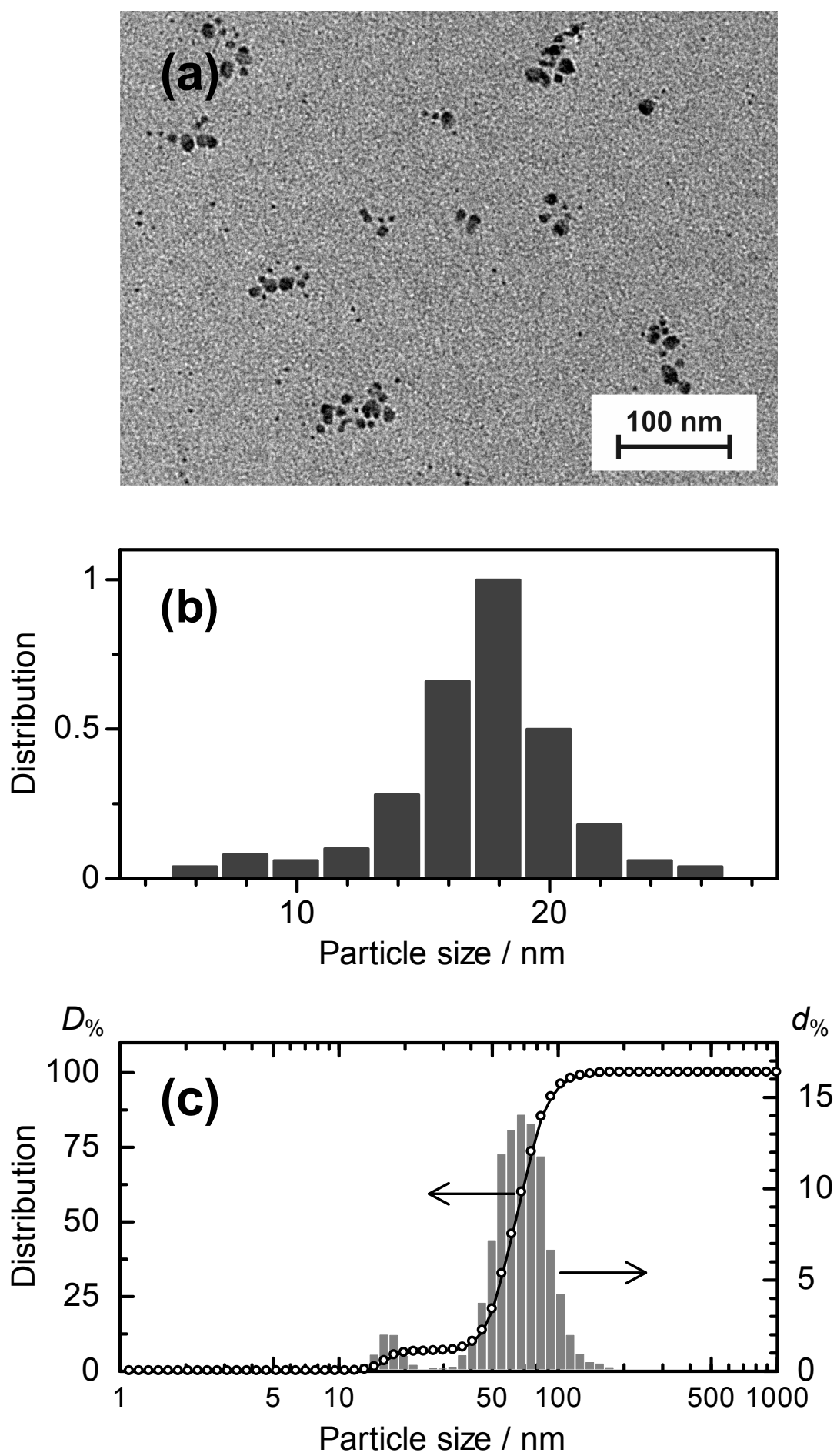
Scheme 1
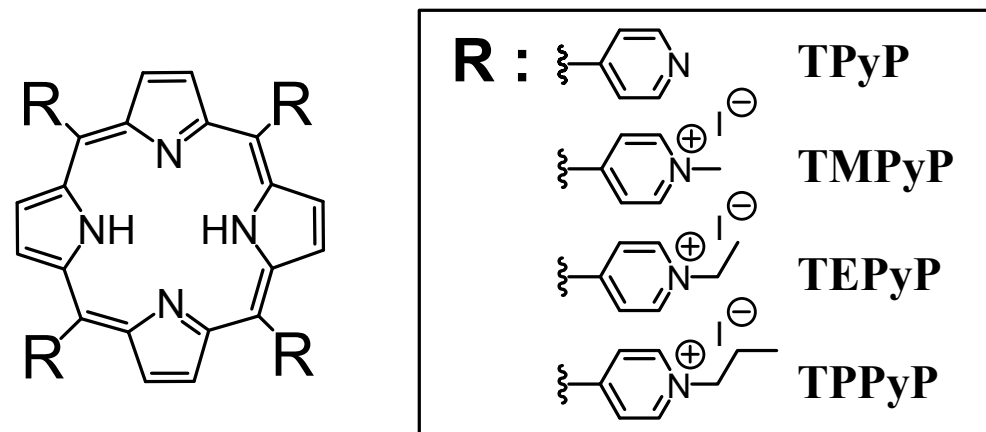
Scheme 2

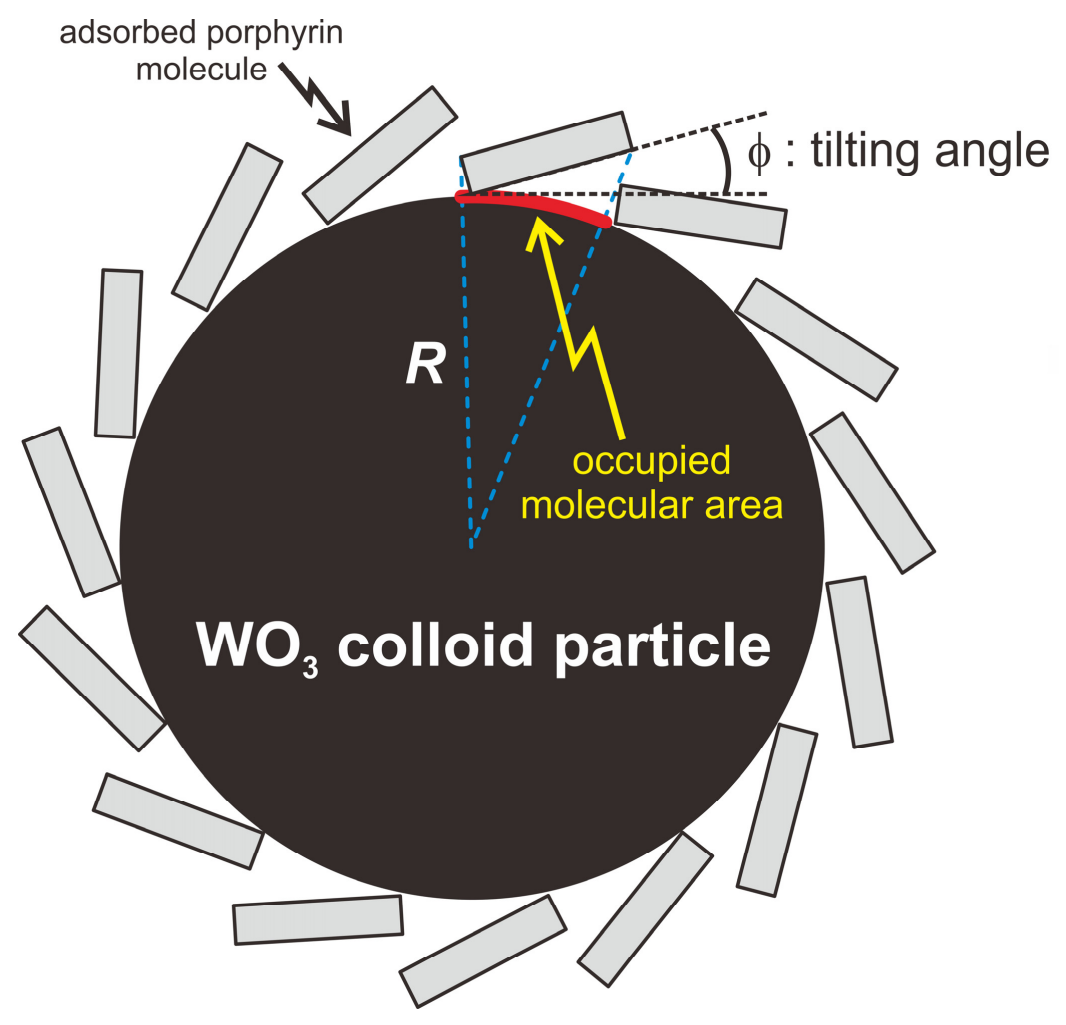




\section{Scheme 3}

(a)

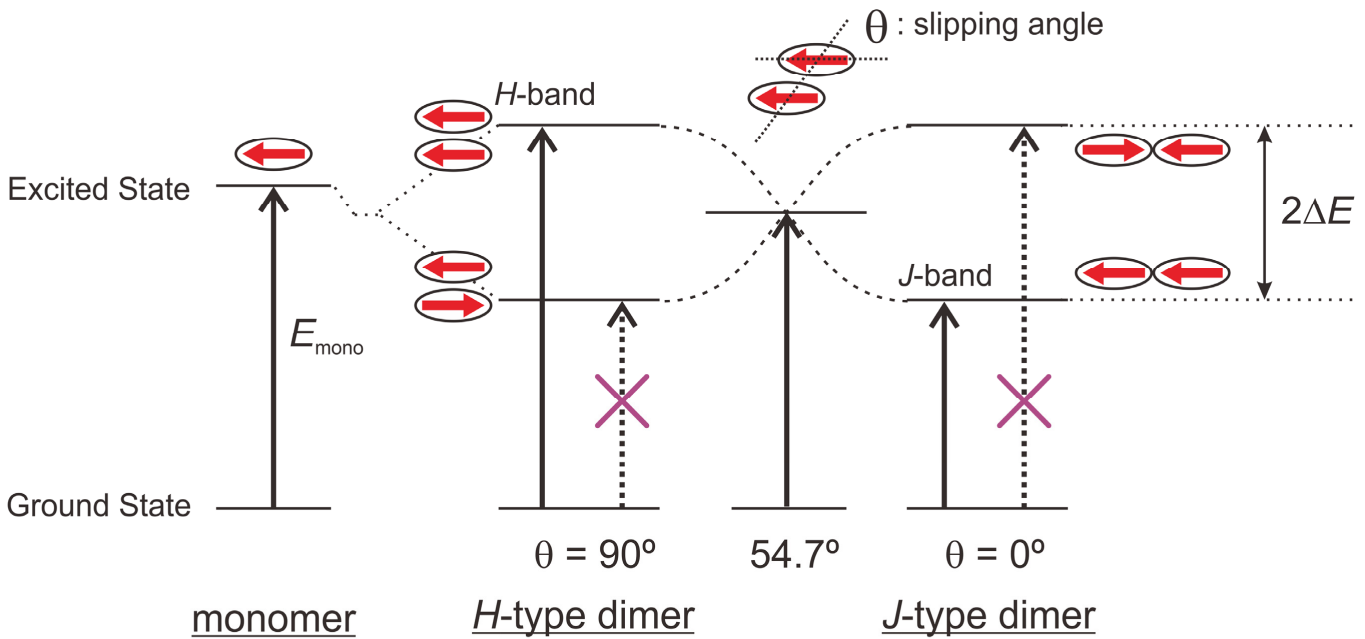

(b)

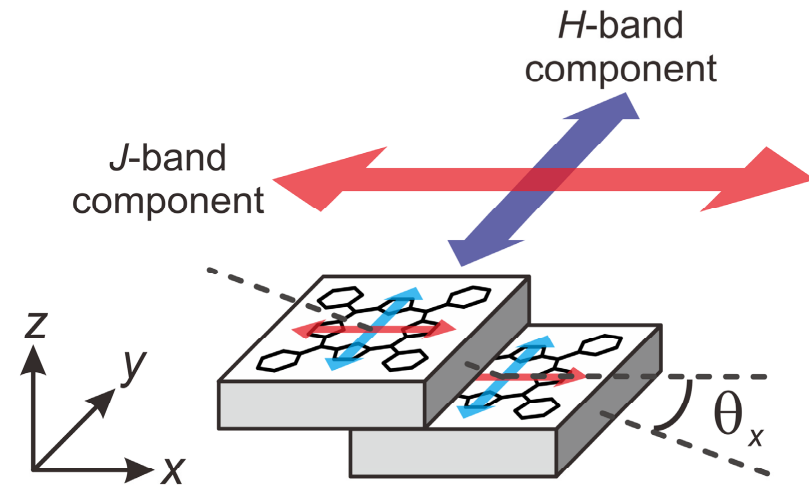

slipping angle 
Table 1 Spectroscopic parameters of aggregate, saturated concentrations $(a)$, aggregation constants $\left(K_{\text {agg(dimer })}\right)$ of TPyP derivatives on the $\mathrm{WO}_{3}$ colloid surface, adsorption constants $\left(K^{\prime}\right)$ onto the $\mathrm{WO}_{3}$ colloid surface at $25^{\circ} \mathrm{C}$, the tilting angles $(\phi)$ of the porphyrin plane from the tangent line to the $\mathrm{WO}_{3}$ particle surface, and the slipping angles $\left(\theta_{x}\right)$ between the $x$-axis transition moment along the slipping direction and the line connecting the molecular centers.

\begin{tabular}{|c|c|c|c|c|c|c|}
\hline Dye & Ion strength $/ \mathrm{mol} \mathrm{dm}^{-3}$ & $a / \mathrm{mol} \mathrm{dm}^{-2}$ & $K_{\text {agg(dimer })}^{\prime} / \mathrm{mol}^{-1} \mathrm{dm}^{2}$ & $K^{\prime} / \mathrm{dm}$ & $\phi /$ degree & $\theta_{x} /$ degree \\
\hline \multirow{3}{*}{ ТРуР } & 0.01 & $(1.15 \pm 0.19) \times 10^{-8}$ & $(1.11 \pm 0.42) \times 10^{8}$ & $(8.23 \pm 0.33) \times 10^{-2}$ & 29.0 & 27.1 \\
\hline & 0.05 & $"$ & $"$ & $(6.39 \pm 0.29) \times 10^{-2}$ & ------ & ------ \\
\hline & 0.1 & $"$ & $"$ & $(4.24 \pm 0.28) \times 10^{-2}$ & ------ & ------- \\
\hline \multirow{3}{*}{ TMPуP } & 0.01 & $(0.93 \pm 0.12) \times 10^{-8}$ & $(1.25 \pm 0.47) \times 10^{8}$ & $(4.58 \pm 0.27) \times 10^{-2}$ & 22.6 & 21.3 \\
\hline & 0.05 & $"$ & $"$ & $(3.62 \pm 0.29) \times 10^{-2}$ & ------- & ------- \\
\hline & 0.1 & $"$ & $"$ & $(2.78 \pm 0.30) \times 10^{-2}$ & ------- & ------- \\
\hline \multirow{3}{*}{ TEPyP } & 0.01 & $(0.83 \pm 0.21) \times 10^{-8}$ & $(1.44 \pm 0.52) \times 10^{8}$ & $(3.38 \pm 0.31) \times 10^{-2}$ & 21.7 & 20.2 \\
\hline & 0.05 & $"$ & $"$ & $(2.97 \pm 0.31) \times 10^{-2}$ & ------- & ------- \\
\hline & 0.1 & $"$ & $"$ & $(2.37 \pm 0.21) \times 10^{-2}$ & ------ & ------- \\
\hline \multirow{3}{*}{ ТРРуР } & 0.01 & $(0.71 \pm 0.16) \times 10^{-8}$ & $(1.51 \pm 0.66) \times 10^{8}$ & $(3.03 \pm 0.36) \times 10^{-2}$ & 20.7 & 19.3 \\
\hline & 0.05 & $"$ & $"$ & $(2.75 \pm 0.34) \times 10^{-2}$ & ------- & ------- \\
\hline & 0.1 & $"$ & $"$ & $(1.98 \pm 0.32) \times 10^{-2}$ & ------- & ------- \\
\hline
\end{tabular}




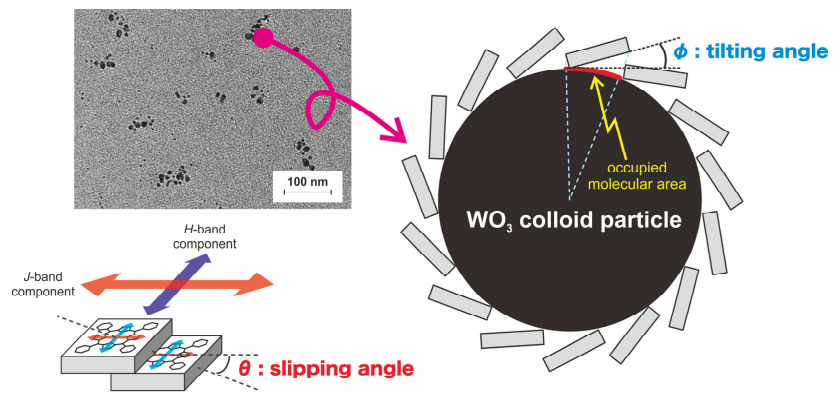

Slipping angle $\boldsymbol{\theta} \fallingdotseq$ Tilting angle $\boldsymbol{\phi}$ This means... 